\title{
Rancang Bangun Media Pembelajaran IPA (Ayo Mengenal Hewan dan Tumbuhan) Untuk Kelas IV SD Berbasis Android
}

\author{
Yogiyana Aditama, Devi Afriyantari Puspa Putri \\ Program Studi Informatika \\ Universitas Muhammadiyah Surakarta (UMS) \\ Surakarta, Indonesia \\ yogiyanaaditama@gmail.com, dapi29@ums.ac.id
}

\begin{abstract}
Abstraksi- Mata pelajaran yang mempunyai keterkaitan dengan kehidupan sehari-hari adalah IPA, hal yang dipelajari oleh siswa-siswi adalah pengelompokan hewan, siklus hidup hewan, dan tumbuh-tumbuhan. Namun dalam proses belajar mengajar siswa-siswi kurang termotivasi karena proses belajar mengajar yang kurang menarik. Berdasarkan masalah tersebut dibuatlah media pembelajaran IPA berbasis android untuk kelas 4 SD karena siswa-siswi masih memiliki ketertarikan yang tinggi terhadap smartphone android dan animasi. Penelitian ini bertujuan untuk menghasilkan sebuah media pembelajaran IPA yang interaktif dan menyenangkan sehingga siswa-siswi dapat mempelajari pembelajaran IPA dengan mudah dan menyenangkan. Metode waterfall adalah metode yang digunakan untuk pembuatan aplikasi ini. Tahap testing aplikasi dalam penelitian ini menggunakan metode pengujian black box testing dan user acceptance test dengan siswa-siswi dan guru sebagai responden. Dari seluruh hasil pengujian dan penyebaran kuisioner yang menunjukkan nilai rata-rata 93,4\% maka dapat disimpulkan aplikasi ini dapat berjalan sesuai yang diharapkan serta dapat menjadi media pembelajaran untuk siswa-siswi.
\end{abstract}

Katakunci-Android; Animasi; Hewan \& Tumbuhan; IPA; Media Pembelajaran

\section{PENDAhULUAN}

Saat iniperkembangan teknologi mengalami kemajuan yang sangat pesat [1], hal ini dibuktikan dengan banyaknya kemunculan software dan hardware baru yang belum pernah ada sebelumnya. Salah satu hal baru dalam sisi software adalah munculnya sistem operasi mobile baru bernama Android. Android menjadi sistem operasi yang kini jamak di gunakan di ponsel pintar (smartphone). Saat ini penggunaan smartphone telah merambah seluruh tingkatan usia termasuk anak-anak, salah satu alasan anak-anak menggemari smartphone adalah adanya software berbasis animasi pada smartphone tersebut [2].

Apabila dibandingkan dengan penggunaan buku teks, aplikasi multimedia sebagai alat bantu pembelajaran ternyata terbukti bisa menambah ketertarikan dan pemahaman siswa dalam mempelajari materi[3].

Dalam proses belajar-mengajar IPA masih menggunakan cara konvensional yang cenderung kurang menarik dan membosankan sehingga siswa-siswi kurang maksimal dalam menerima pengetahuan yang mereka peroleh dari sekolah [4].

Berdasarkan masalah diatas penulis bermaksud untuk membuat media belajar yang menarik dan mengasyikkan untuk siswa-siswi yaitu media pembelajaran IPA untuk kelas IV SD berbasis Android. Media pembelajaran berbasis animasi merupakan metode pembelajaran yang cukup perlu dipertimbangkan hal itu berdasarkan kebiasaan anak-anak yang lebih gemar bermain dibandingkan belajar serta masih memiliki ketertarikan yang tinggi terhadap game atau animasi.

\section{TINJAUAN PUSTAKA}

Penelitian terdahulu yang berjudul "Game Edukasi Pengenalan Cara Hidup Hewan Dan Tumbuhan Untuk Anak Usia Sekolah Dasar Kelas 4" oleh [5] dengan menggunakan software Macromedia Flash menghasilkan sebuah game edukasi yang dapat membantu dan memotivasi siswa dalam memaksimalkan hasil belajarnya. Sedangkan penelitian berjudul "Game Edukasi Berbasis Android Sebagai Media Pembelajaran Untuk Anak Usia Dini" oleh [6] menghasilkan sebuah game pengenalan hewan dan mewarnai untuk anak usia dibawah 6 tahun, aplikasi ini dibuat dengan menggunakan software app inventor, pembuatan aplikasi ini bertujuan untuk memperkenalkan materi dengan lebih menarik dan menyenangkan.

Berdasarkan kedua penelitian tersebut terdapat kesamaan tujuan antara penulis dan peneliti terdahulu yaitu menciptakan media pembelajaran yang menarik dan menyenangkan serta dapat memotivasi minat belajar anak. Dalam pembuatannya tentu saja terdapat beberapa perbedaan salah satunya adalah software yang penulis gunakan pada pembuatan aplikasi media pembelajaran ini adalah Construct 2 karena keunggulan 
Construct 2 adalah multiplatform sehingga dapat mempublikasikan hasil dari penelitian ini ke beberapaplatform hanya dengan satu project saja.

\section{METODE}

Metode System Development Life Cycle (SDLC) adalah metode yang penulis gunakan, SDLC sering disebut dengan metode waterfall.Dalam penelitian ini penulis menggunakan metode waterfall versi Sommerville, sebab metode waterfall ini merupakan pengembangan terbaru dari metode waterfall yang telah dikembangkan sebelumnya. Gambaran tentang metode waterfall yang penulis gunakan tergambar di dalam diagram proses penelitian pada Gambar 1 dibawah ini.

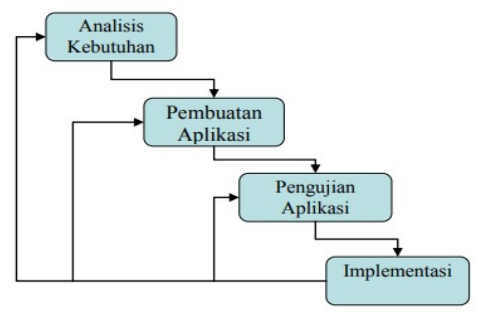

Gambar 1. Diagram proses penelitian

\section{A. Analisis Kebutuhan}

Tahap analisis kebutuhan ini dilakukan untuk mengetahui kebutuhan apa saja yang dibutuhkan untuk melakukan perancangan aplikasi yang bertujuan agar aplikasi dapat selesai pada waktunya dengan hasil akhir yang memuaskan. Beberapa kebutuhan dalam pembuatan aplikasi ini adalah kebutuhan hardware dan software, yang dipaparkan di Tabel 1 .

TABELI.ANALISIS KEBUTUHAN HARDWARE DAN SOFTWARE

\begin{tabular}{|l|ll|}
\hline Kebutuhan Hardware & \multicolumn{1}{|c|}{ Kebutuhan Software } \\
\hline 1. Notebook Asus A455L, & 1. Windows 8.1 Pro 64 Bit \\
processor Intel $®$ Core I3, & 2. Construct 2 v.r244 \\
CPU @2.70GHz, RAM & 3. Format Factory v.3.80 \\
4GB & 4. CorelDRAW X7 \\
2. Smartphone Android & 5. Google Chrome \\
Lenovo $^{\mathrm{TM}}$ A6010 & 6. Website www.phonegap.com \\
\hline
\end{tabular}

\section{B. Pembuatan Aplikasi}

Tahapan pertama yang dilakukan sebelum perancangan aplikasi, dibuat diagram alir perancangan aplikasi agar dalam proses pembuatan aplikasi terfokus dan teratur, lalu dilakukan pengumpulan data dan materi yang akan diimplementasikan ke dalam game, data dan materi itu meliputi perancangan assetsgame baik itu gambar ataupun suara. Diagram alir perancangan aplikasi dijabarkan dalam Gambar 2.

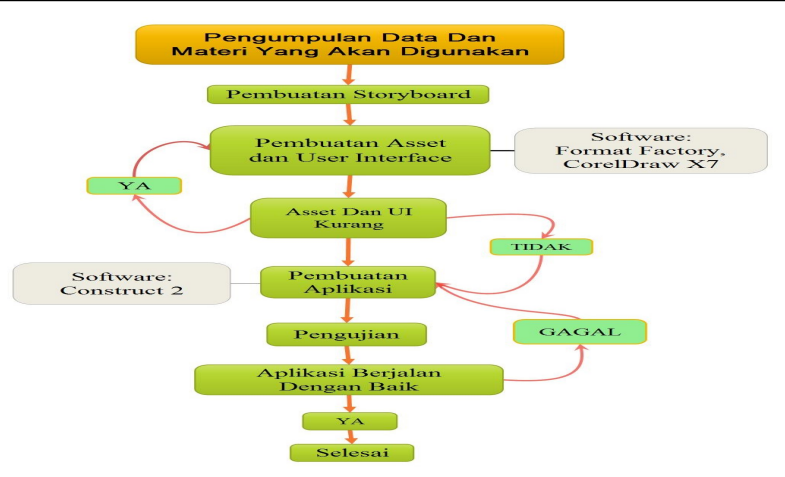

Gambar 2.Diagram Proses Perancangan Aplikasi

\section{Pengujian Aplikasi}

Pengujian aplikasi atau perangkat lunak adalah proses menjalankan atau memeriksa perangkat lunak dengan cara manual ataupun otomatis untuk mengetahui apakah software sudah memenuhi persyaratan atau perlu adanya perbaikan[7].

Pada pengujian aplikasi ini terdapat dua metode pengujian yaitu metode blacx box testing dan UAT ( User Acceptance Test) atau tingkat penerimaan pengguna. Metode black box testing menjadi metode yang cukup relevan mengingat nantinya tester software ini merupakan individu yang masih awam tentang software dan teknologi informasi, sedangkan UAT merupakan tahapan pengujian yang dilakukan oleh user calon pengguna aplikasi, dalam pengujian ini menghasilkan dokumen fisik sebagai bukti bahwa aplikasi yang dirancang telah valid oleh user dan hasil pengujiannya telah memenuhi kebutuhan pengguna[8], oleh karena itu dibuatlah kuisioner dengan menggunakan skala likert 5 skala yaitu Sangat Tidak Setuju (STS), Tidak Setuju (TS), Neutral (N), Setuju (S), Sangat Setuju (SS) untuk memudahkan pengumpulan data. Adapun kuisioner tersebut ditunjukkan pada Tabel 2.

TABEL II. KUISIONER PENGUJIAN APLIKASI

\begin{tabular}{|c|c|c|c|c|c|c|}
\hline \multirow{2}{*}{ No } & \multirow{2}{*}{ Pertanyaan } & \multicolumn{5}{|c|}{ Pilihan Jawaban } \\
\hline & & SS & $\mathbf{S}$ & $\mathbf{N}$ & TS & STS \\
\hline 1. & Apakah aplikasi ini menarik? & & & & & \\
\hline 2. & $\begin{array}{l}\text { Apakah aplikasi ini mudah } \\
\text { digunakan? }\end{array}$ & & & & & \\
\hline 3. & $\begin{array}{l}\text { Apakah tombolnya mudah dimengerti } \\
\& \text { mudah digunakan? }\end{array}$ & & & & & \\
\hline 4. & $\begin{array}{l}\text { Apakah bahasa yang digunakan } \\
\text { mudah dimengerti? }\end{array}$ & & & & & \\
\hline 5. & $\begin{array}{l}\text { Apakah materi pembelajaran mudah } \\
\text { dipahami? }\end{array}$ & & & & & \\
\hline 6. & $\begin{array}{l}\text { Apakah tampilan aplikasi tidak } \\
\text { membosankan? }\end{array}$ & & & & & \\
\hline 7. & $\begin{array}{l}\text { Apakah pertanyaan kuis mudah } \\
\text { dijawab? }\end{array}$ & & & & & \\
\hline 8. & $\begin{array}{l}\text { Apakah aplikasi ini membantu belajar } \\
\text { materi pembelajaran mengenal hewan } \\
\& \text { tumbuhan disekitar kita? }\end{array}$ & & & & & \\
\hline 9. & $\begin{array}{l}\text { Apakah aplikasi ini mampu } \\
\text { meningkatkan minat belajar IPA? }\end{array}$ & & & & & \\
\hline 10. & $\begin{array}{l}\text { Apakah tombol berfungsi dengan } \\
\text { baik? }\end{array}$ & & & & & \\
\hline
\end{tabular}




\section{Implementasi}

Tahap implementasi adalah tahapan terakhir pada metode yang digunakan penulis. Pada tahap ini software akan diperkenalkan dan memberipelatihan tentang pengoperasian aplikasi ini kepada siswa-siswi kelas 4 SD Negeri 1 Repaking beserta guru, agar nantinya aplikasi dapat dimanfaatkan dengan sebagaimana mestinya.

\section{HASIL DAN PEMBAHASAN}

Setelah tahapan sebelumnya telah selesai dilakukan maka pada penelitian ini menghasilkan sebuah aplikasi media pembelajaran (Ayo Mengenal Hewan Dan Tumbuhan Di Sekitar Kita). Mengenai hasil dari Perancangan dan pembuatan aplikasi ini dijelaskan sepertiberikut :

\section{A. Hasil Tampilan Aplikasi}

\section{Halaman Menu Awal}

Di halaman menu awal ini adalah tampilan permualaan dari aplikasi adapun tampilannya di tunjukkan pada Gambar 3.

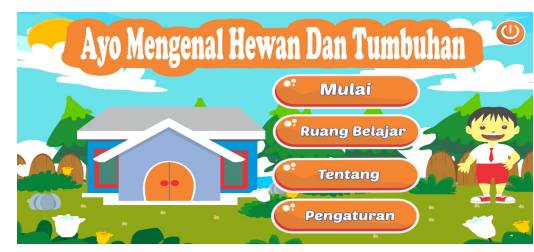

Gambar 3. Halaman awal aplikasi

Pada halaman awal ini terdapat dua menu pendukung aplikasi berupa menu tentang dan menu pengaturan yang tampilannya ditunjukan pada Gambar 4 dan 5 dibawah ini.

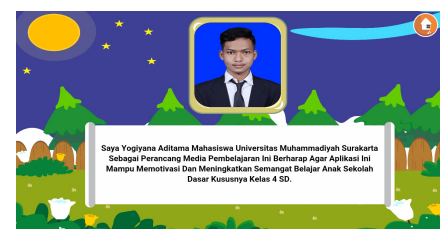

Gambar 4. Halaman tentang

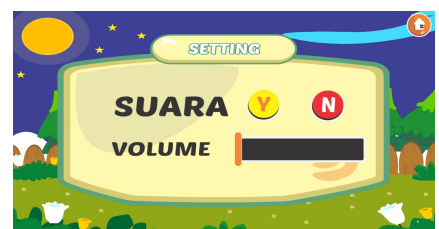

Gambar 5. Halaman Pengaturan

\section{Menu Mulai}

Pada halaman mulai ketika user mengklik tombol mulai maka ditampilkan halaman kuis yang berisi 35 soal dari materi ruang belajar, apabila user salah memilih jawaban atau waktu habis lalu penggunaakan dialihkan menuju halaman game over.Mengenai tampilannya ditunjukkan pada Gambar 6 dan Gambar 7.

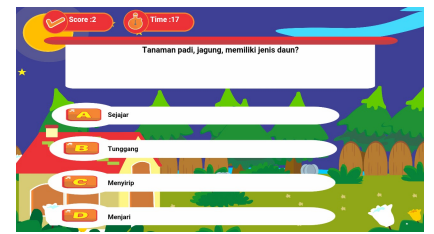

Gambar 6. Halaman Kuis

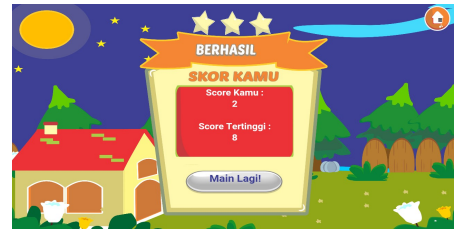

Gambar 7. Halaman game over

\section{Menu Ruang Belajar}

Dalam menu ruang belajar terdapat materi tentang pengenalan hewan dan tumbuhan disekitar kita serta materi siklus hidup hewan dan tumbuhan, user juga diberikan pilihan ingin mempelajari materi hewan dahulu atau tumbuhan dahulu.Materi keduanya ditampilkan dalam bentuk gambar dan penjelasan yang dapat digeser ke arah kiri atau kanan.Adapun tampilan dari menu ruang belajar ditunjukkan di Gambar 8.

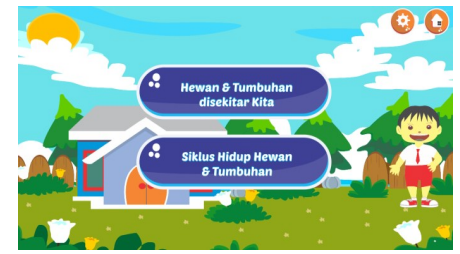

(a)

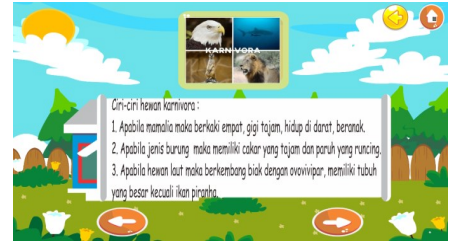

(c)

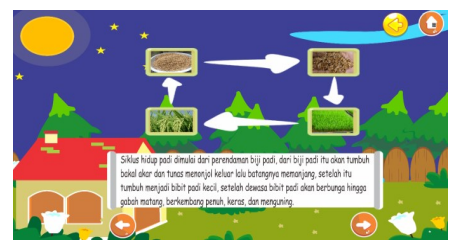

(e)

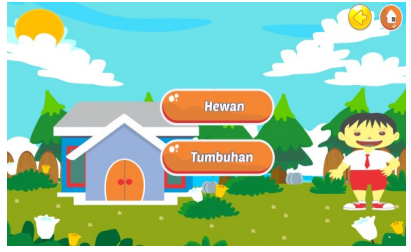

(b)

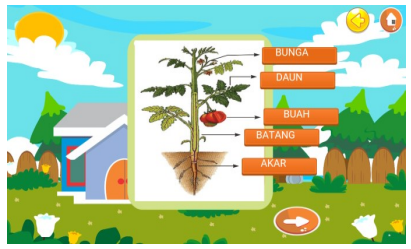

(d)

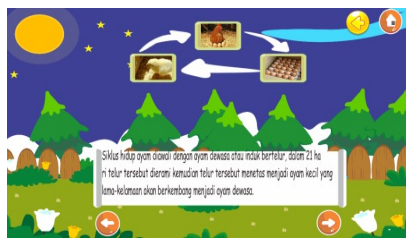

(f)
Gambar 8. Halaman Sub Menu Ruang Belajar (a), Halaman Pilihan Materi Hewan Atau Tumbuhan (b), Halaman Materi Pengenalan Hewan (c), Halaman Materi Pengenalan Tumbuhan (d), Halaman Materi Siklus Hidup Tumbuhan (e), Halaman Materi Siklus Hidup Hewan (f)

\section{B. Pengujian Blackbox}

Dalam tahap ini dilakukan sebuah metode pengujian software bernama black box, pengujian ini memiliki tujuan guna mengetahui apakah aplikasi ini telah berjalan sesuai dengan fungsi yang penulis harapkan sebelumnya.Pengujian black box pada aplikasi ini didapatkan hasil yang dijelaskan dalam Tabel 3.

TABEL III. HASIL PENGUJIAN BLACKBOX

\begin{tabular}{|c|c|c|c|c|}
\hline Bagian & $\begin{array}{c}\text { Nama } \\
\text { Pengujian }\end{array}$ & $\begin{array}{c}\text { Bentuk } \\
\text { Pengujian }\end{array}$ & $\begin{array}{c}\text { Hasil Yang } \\
\text { Diharap }\end{array}$ & Hasil \\
\hline \multirow{3}{*}{$\begin{array}{c}\text { Menu } \\
\text { Utama }\end{array}$} & Mulai Kuis & Klik "Mulai" & $\begin{array}{c}\text { Muncul } \\
\text { Halaman Kuis }\end{array}$ & Valid \\
\cline { 2 - 5 } & $\begin{array}{c}\text { Mulai } \\
\text { Belajar }\end{array}$ & $\begin{array}{c}\text { Klik "Ruang } \\
\text { Belajar" }\end{array}$ & $\begin{array}{c}\text { Muncul Pilihan } \\
\text { Materi }\end{array}$ & Valid \\
\cline { 2 - 5 } & $\begin{array}{c}\text { Menu } \\
\text { Tentang }\end{array}$ & Klik "Tentang" & $\begin{array}{c}\text { Muncul } \\
\text { Halaman } \\
\text { Tentang }\end{array}$ & Valid \\
\hline
\end{tabular}




\begin{tabular}{|c|c|c|c|c|}
\hline Bagian & $\begin{array}{c}\text { Nama } \\
\text { Pengujian }\end{array}$ & $\begin{array}{c}\text { Bentuk } \\
\text { Pengujian }\end{array}$ & $\begin{array}{c}\text { Hasil Yang } \\
\text { Diharap }\end{array}$ & Hasil \\
\hline & $\begin{array}{c}\text { Menu } \\
\text { Pengaturan }\end{array}$ & $\begin{array}{c}\text { Klik } \\
\text { "Pengaturan" }\end{array}$ & $\begin{array}{c}\text { Muncul } \\
\text { Halaman } \\
\text { Pengaturan }\end{array}$ & Valid \\
\hline \multirow[t]{3}{*}{$\begin{array}{c}\text { Halama } \\
\text { n Kuis }\end{array}$} & $\begin{array}{l}\text { Pengujian } \\
\text { Kuis }\end{array}$ & Klik "Mulai" & $\begin{array}{l}\text { Menampilkan } \\
35 \text { Soal Acak }\end{array}$ & Valid \\
\hline & $\begin{array}{l}\text { Penghitung } \\
\text { an Score }\end{array}$ & Menjawab Kuis & $\begin{array}{c}\text { Muncul } \\
\text { Tampilan Score } \\
\text { Dan Highscore }\end{array}$ & Valid \\
\hline & $\begin{array}{c}\text { Pengujian } \\
\text { Jawaban }\end{array}$ & $\begin{array}{c}\text { Mengklik } \\
\text { Jawaban }\end{array}$ & $\begin{array}{c}\text { Jika Benar } \\
\text { Menambah } \\
\text { Score Jika Salah } \\
\text { Game Over }\end{array}$ & Valid \\
\hline $\begin{array}{l}\text { Halam } \\
\text { an } \\
\text { Game } \\
\text { Over }\end{array}$ & $\begin{array}{l}\text { UI Game } \\
\text { Over }\end{array}$ & $\begin{array}{c}\text { Menyelesaikan } \\
\text { Kuis }\end{array}$ & $\begin{array}{l}\text { Menampilkan } \\
\text { Score Dan High } \\
\text { Score }\end{array}$ & Valid \\
\hline \multirow{3}{*}{$\begin{array}{l}\text { Halam } \\
\text { an } \\
\text { Game } \\
\text { Over }\end{array}$} & $\begin{array}{l}\text { Keluar } \\
\text { Kuis }\end{array}$ & Klik "Home" & $\begin{array}{c}\text { Muncul Pop Up } \\
\text { Pertanyaan } \\
\text { Konfirmasi }\end{array}$ & Valid \\
\hline & $\begin{array}{l}\text { Pengujian } \\
\text { Pop Up }\end{array}$ & $\begin{array}{c}\text { Mengklik } \\
\text { Tombol "YA" } \\
\text { dan "Tidak" }\end{array}$ & $\begin{array}{c}\text { Jika Ya Keluar } \\
\text { Quis, Jika Tidak } \\
\text { Tetap Pada } \\
\text { Halaman Game } \\
\text { Over } \\
\end{array}$ & Valid \\
\hline & $\begin{array}{l}\text { Mengulang } \\
\text { Kuis }\end{array}$ & $\begin{array}{c}\text { Mengklik } \\
\text { Tombol Main } \\
\text { Lagi } \\
\end{array}$ & $\begin{array}{c}\text { Memulai Ulang } \\
\text { Kuis }\end{array}$ & Valid \\
\hline \multirow{4}{*}{$\begin{array}{l}\text { Halam } \\
\text { an } \\
\text { Ruang } \\
\text { Belajar }\end{array}$} & $\begin{array}{c}\text { Pengujian } \\
\text { Materi } \\
\text { Pengenalan } \\
\text { Hewan } \\
\end{array}$ & $\begin{array}{c}\text { Mengklik } \\
\text { Tombol Hewan }\end{array}$ & $\begin{array}{c}\text { Menampilkan } \\
\text { Materi } \\
\text { Pengenalan } \\
\text { Hewan }\end{array}$ & Valid \\
\hline & $\begin{array}{l}\text { Pengujian } \\
\text { Materi } \\
\text { Siklus } \\
\text { Hidup } \\
\text { Hewan }\end{array}$ & $\begin{array}{c}\text { Mengklik } \\
\text { Tombol Siklus } \\
\text { Hidup Hewan }\end{array}$ & $\begin{array}{l}\text { Menampilkan } \\
\text { Materi Siklus } \\
\text { Hidup Hewan }\end{array}$ & Valid \\
\hline & $\begin{array}{l}\text { Pengujian } \\
\text { Materi } \\
\text { Pengenalan } \\
\text { Tumbuhan } \\
\end{array}$ & $\begin{array}{l}\text { Mengklik } \\
\text { Tombol } \\
\text { Tumbuhan }\end{array}$ & $\begin{array}{c}\text { Menampilkan } \\
\text { Materi } \\
\text { Pengenalan } \\
\text { Tumbuhan }\end{array}$ & Valid \\
\hline & $\begin{array}{c}\text { Pengujian } \\
\text { Materi } \\
\text { Siklus } \\
\text { Hidup } \\
\text { Tumbuhan } \\
\end{array}$ & $\begin{array}{c}\text { Mengklik } \\
\text { Tombol Siklus } \\
\text { Hidup } \\
\text { Tumbuhan }\end{array}$ & $\begin{array}{c}\text { Menampilkan } \\
\text { Materi Siklus } \\
\text { Hidup } \\
\text { Tumbuhan }\end{array}$ & Valid \\
\hline \multirow{2}{*}{$\begin{array}{l}\text { Halam } \\
\text { an } \\
\text { Pengat } \\
\text { uran }\end{array}$} & $\begin{array}{c}\text { Pengujian } \\
\text { Mute/Unmu } \\
\text { teAudio }\end{array}$ & $\begin{array}{l}\text { Klik Tombol } \\
\text { "Y"/"N" }\end{array}$ & $\begin{array}{c}\text { AudioMute dan } \\
\text { Unmute }\end{array}$ & Valid \\
\hline & $\begin{array}{l}\text { Pengaturan } \\
\text { Volume }\end{array}$ & $\begin{array}{c}\text { Menggeser } \\
\text { Slider Volume }\end{array}$ & $\begin{array}{l}\text { Volume } \\
\text { Berubah Sesuai } \\
\text { Pergeseran } \\
\text { Slider }\end{array}$ & Valid \\
\hline $\begin{array}{c}\text { Keselu } \\
\text { ruhan } \\
\text { Aplika } \\
\text { si }\end{array}$ & $\begin{array}{l}\text { Fungsi } \\
\text { Tombol }\end{array}$ & $\begin{array}{l}\text { Klik Setiap } \\
\text { Tombol }\end{array}$ & $\begin{array}{c}\text { Tombol } \\
\text { Berjalan Sesuai } \\
\text { Fungsinya }\end{array}$ & Valid \\
\hline
\end{tabular}

Dari hasil pengujian Blackbox diatas maka bisa disimpulkan bahwa seluruh fitur yang terdapat di aplikasi ini mampu berjalan dengan lancar dan baik sesuai dengan fungsinya.

Pengujian yang lain setelah black box testing aplikasi, pengetesan juga dilakukan pada smarthone android, dimana smartphone android sendiri menjadi platform dimana aplikasi ini beroperasi. Hasil Pengujian perangkat dijelaskan pada Tabel 4.

TABEL IV. HASIL PENGUJIAN PERANGKAT

\begin{tabular}{|c|c|c|}
\hline Merk & Spesifikasi & Hasil \\
\hline Samsung Galaxy & Layar 5,5inch, Ram & Dapat Terbuka, Berjalan \\
J7 Prime & 3GB,Octacore, & Lancar \\
& Marshmallow & \\
\hline Lenovo A6010 & Layar 5,0inch, RAM & Dapat Terbuka, Berjalan \\
Plus & 2GB,Quadcore, & Lancar \\
& Lolipop & \\
\hline Samsung Galaxy & Layar 5,0inch, RAM & Dapat Terbuka, Force \\
Grand Prime & 1GB, Quadcore, & Close Pada Halaman \\
& Kitkat & Ruang Belajar \\
\hline
\end{tabular}

Dari tabel pengujian perangkat tersebut dapat ditarik kesimpulan yaitu aplikasi ini mampu berjalan lancar di smartphone platform android, tetapi pada smartphone dengan spesifikasi yang rendah terkadang terjadi force close dan lag saat membuka halaman tertentu, namun secara keseluruhan aplikasi ini sudah dapat berjalan dengan baik pada perangkat smartphone android.

\section{Pengetesan Kepada Calon User Aplikasi}

Pengujian kepada calon user aplikasi ini diterapkan kepada guru dan siswa-siswi kelas IV SD Negeri II Repaking Kabupaten Boyolali dengan menyeberkan kuisioner user acceptance test yang telah dijelaskan pada tahap sebelumnya. Koresponden pengujian ini adalah 6 guru dan 24 siswa-siswi jadi total koresponden keseluruhan berjumlah 30 orang. Dalam penelitian kuantitatif total sampel yang wajar pada penelitian adalah sekitar 30 sampai dengan 500 respondem[9].

Berdasarkan hasil rekapitulasi kuisioner maka skor ideal (kriterium) dihitung dengan menggunakan rumus persamaan 1 .

$$
\text { SkorIdeal }=\sum 5 \times \text { JumlahResponden }
$$

Keterangan : 5 didapat dari nilai skala SS (Sangat Setuju).

Jadi skor ideal (kriterium) dalam kuisioner ini adalah $5 \mathrm{x}$ $30=150$.

Sedangkan untuk menghitung presentase persetujuan dari hasil kuisioner diatas dapat dihitung dengan menggunaka rumus persamaan 2 berikut ini.

$$
\text { presentase }=\frac{\text { nilai }}{\text { skorideal }} \cdot 100 \%
$$

Dari kedua rumus persamaan diatas dapat disimpulkan hasil dari kuisioner user acceptance test seperti pada Tabel 5 dibawah ini. 
TABEL V. HASIL PENGUJIAN USER ACCEPTANCE TEST

\begin{tabular}{|c|c|c|c|c|c|c|c|c|}
\hline \multirow{2}{*}{ No } & \multirow{2}{*}{$\begin{array}{c}\text { Pertanya } \\
\text { an }\end{array}$} & \multicolumn{5}{|c|}{ Jumlah Jawaban } & \multirow{2}{*}{$\begin{array}{c}\text { Total } \\
\text { Skor }\end{array}$} & $\begin{array}{c}\text { Persentase } \\
\text { Nilai }\end{array}$ \\
\cline { 3 - 7 } & & SS & S & N & TS & $\begin{array}{c}\text { ST } \\
\text { S }\end{array}$ & & \\
\hline 1. & P1 & 23 & 6 & 1 & 0 & 0 & 142 & $94,7 \%$ \\
\hline 2. & P2 & 20 & 9 & 1 & 0 & 0 & 139 & $92,7 \%$ \\
\hline 3. & P3 & 17 & 11 & 2 & 0 & 0 & 135 & $90 \%$ \\
\hline 4. & P4 & 18 & 12 & 0 & 0 & 0 & 138 & $92 \%$ \\
\hline 5. & P5 & 17 & 13 & 0 & 0 & 0 & 137 & $91,3 \%$ \\
\hline 6. & P6 & 22 & 8 & 0 & 0 & 0 & 142 & $94,7 \%$ \\
\hline 7. & P7 & 19 & 11 & 0 & 0 & 0 & 139 & $92,7 \%$ \\
\hline 8. & P8 & 23 & 6 & 1 & 0 & 0 & 142 & $94,7 \%$ \\
\hline 9. & P9 & 23 & 7 & 0 & 0 & 0 & 143 & $95,3 \%$ \\
\hline 10. & P10 & 24 & 6 & 0 & 0 & 0 & 144 & $96 \%$ \\
\hline \multicolumn{8}{|c|}{ Nilai Presentase Rata-Rata } \\
\hline
\end{tabular}

Hasil dari pengujianuser acceptance test diatas diperjelas dalam bentuk diagram batang pada Gambar 9 .

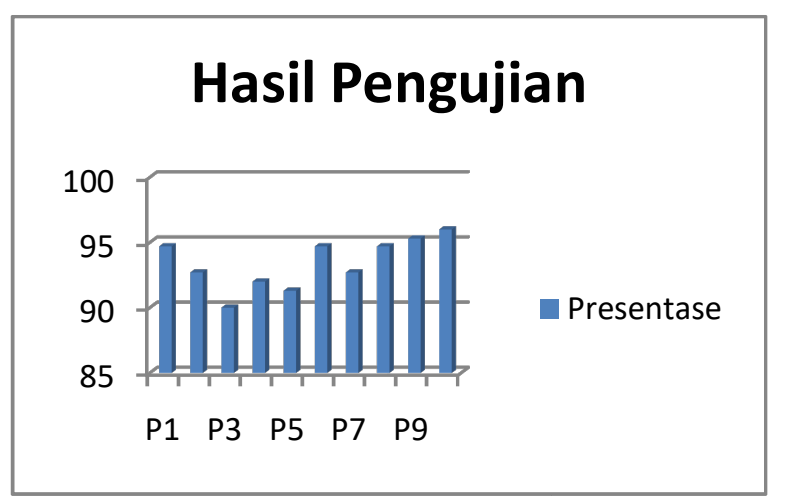

Gambar 9. Diagram hasil penghitungan kuisioner

\section{KESIMPULAN}

Setelah tahap analisis, pembuatan aplikasi, dan pengujian terhadap aplikasi ini telah selesai, penulis menarik kesimpulan yang dijelaskan sebagai berikut.

1. Nilai rata-rata presentase tingkat penerimaan pengguna adalah 93,4\%, hal itu menunjukkan bahwa aplikasi ini menarik perhatian bagi siswa-siswi sekolah dasar kelas 4, serta dapat membantu meningkatkan minat belajar siswasiswi dalam mempelajari lingkungan disekitarnya khususnya tentang hewan dan tumbuhan di sekitar mereka. Aplikasi ini berjalan dengan lancar, bahasanya mudah dimengerti, materi yang terdapat dalam aplikasi ini mudah dipahami, serta tombol-tombol yang ada dapat berjalan sesusai dengan fungsinya.

2. Aplikasi ini mampu berjalan pada smartphone yang memakai sistem operasi android dengan lancar, aplikasi menampilkan tampilan fullscreen pada smartphone android.

\section{DAFTAR PUSTAKA}

[1] M. Ngafifi, "Advances in Technology and Patterns of Human Life in Socio-Cultural Perspective," Kemajuan Teknol. dan Pola Hidup Mns., vol. 2, no. 1, pp. 33-47, 2014.

[2] R. Delima, N. K. Arianti, and B. Pramudyawardani, "Identifikasi Kebutuhan Pengguna Untuk Aplikasi Permainan Edukasi Bagi Anak Usia 4 sampai 6 Tahun," Tek. Inform. dan Sist. Inf., vol. 1, no. April, pp. 1-8, 2015.

[3] H. Supriyono et al., "The 2 nd University Research Coloquium 2015 ISSN 2407-9189 Rancang Bangun Media Pembelajaran Bahasa dan Huruf Jawa Berbasis Adobe Flash CS6 The 2 nd University Research Coloquium 2015 ISSN 2407-9189,” pp. 1-9, 2015.

[4] A. R. Pratiwi, "Pengaruh Gaya Mengajar Guru Terhadap Minat Kebudayaan Islam di MTS Negeri Karanganyar,” 2017.

[5] F. Arifin, T. Abidin, and M. Humam, "Game Edukasi Pengenalan Cara Hidup Hewan dan Tumbuhan Untuk Anak Usia Sekolah Dasar Kelas 4," pp. 54-60, 2003.

[6] D. W. Putra, A. P. Nugroho, and E. W. Puspitarini, "Game Edukasi Sebagai Media Pembelajaran Pendidikan Anak Usia Dini," J. Inform. Merdeka Pasuruan, vol. 1, no. 1, pp. 1-8, 2016.

[7] H. Sulistyanto, "Urgensi Pengujian Pada Kemajemukan Perangkat Lunak Dalam Multi Perspektif," Komuniti, vol. 6, no. 1, pp. 65-74, 2017.

[8] A. B. Mutiara, "Testing Implementasi Website Rekam Medis Elektronik Opeltgunasys Dengan Metode Acceptance Testing," vol. 8, no. Kommit 2014, pp. 1-7, 2015.

[9] P. Sugiyono, “Dr. 2010," Metod. Penelit. Kuantitatif, Kualitatif, dan R\&D. Bandung CV Alf., 2010. 